DOI: 10.12731/2077-1770-2018-4-3-113-126

УДК 821.161.1

\title{
СОПОСТАВИТЕЛЬНЫЙ АНАЛИЗ ИМЕН ЧИСЛИТЕЛЬНЫХ ДАРГИНСКОГО И НЕМЕЦКОГО ЯЗЫКОВ
}

\section{Мишаева М.В., Мутаева С.И.}

Цель. В статье проводится сопоставительный анализ числительных даргинского и немецкого языков. Основная целль нашего исследования заключается в исследовании числительного даргинского языка в последовательном сопоставлении с фактами немецчкого языка.

Метод и методология проведения работы. В работе использованы различные методы исследования: описательный, сопоставительный и структурно-семантический.

Результаты. Авторы отмечают, что по своим образовательным и функциональным признакам числительное в исследуемых языках делится на специфические разряды. Числительные даргинского языка в атрибутивной функции не располагают какой-либо грамматической категорией. Неизменяемость определенных количественных числительных немеикого языка также является одной из отличительных черт грамматического строя данного языка. $B$ немецком языке при сочетании имени числительного с именем существительным проявляются некоторые структурные особенности.

Область применения результатов. Материаль данного исследования могут быть использованы в свете новых требований преподавания даргинского и немецкого языков в школе и в вузе.

Ключевые слова: даргинский язык; немецкий язык; имена числительнье; количественные; порядковые; дробньле; структурносемантические разряды; сопоставительный анализ.

\section{COMPARATIVE ANALYSIS OF NUMERALS IN THE DARGWA AND GERMAN LANGUAGES}

\section{Mishayeva M.V., Mutayeva S.I.}

Purpose. The article presents the comparative analysis of numerals in the Dargwa and German languages. The main purpose of our research 
is to study the Dargwa language numerals in comparison with the similar facts in the German language.

Methodology. When developing the topic, various methods of research were used in the work such as the descriptive, comparative and structural-semantic ones.

Results. The authors note that the numerals in the Dargwa and German languages are divided into specific categories according to their educational and functional characteristics. Numerals in the Dargwa language that have an attribute function do not have any grammatical category. The immutability of certain cardinal numerals of the German language is also one of the distinctive features of the grammatical structure of the language. When combining a numeric name with a noun, some structural features are revealed in the German language.

Practical implications. The materials of the following study can be used at schools and universities, since the introduction of new requirements of teaching the Dargwa and German languages are coming soon.

Keywords: Dargwa language; German language; numerical names; cardinal, ordinal, fractional; structural-semantic categories; comparative analysis.

По своей природе имя числительное одно из самых абстрактных и древних в языке. Исследования показывают, что люди склонны наделять некоторые числительные мистическими, загадочными характеристиками. Респонденты выделяют «счастливые», «несчастливые» числа. Символические значения числительных указывают на то, что в большей своей части эти языковые единицы сформировались в глубоком прошлом нации [8, с. 55]. Лексико-грамматический класс числительных представляет собой сложную систему, в которую включены количественные числительные и лексические единицы, пересекающиеся с другими частями речи. Основанием для объединения такого рода единиц является их количественная семантика [12, с. 5]. Помимо семантического своеобразия ему присущ ряд синтаксических и морфологических черт. Обычно у имен числительных имеются отличительные особенности структурного 
характера. Если имена числительные многих языков сближаются своими семантическими и синтаксическими чертами, то морфологические и структурные особенности по языкам большей частью локализованы. Интересно, в частности, отметить, что числительные не образуются от других частей речи, хотя в то же время могут служить базой для образования других частей речи. Так, например, в современном немецком языке можно обнаружить большое количество слов, в которые входят числительные eins и erst. Среди них огромное количество прилагательных, таких как eindeutig, einfach, einförmig, einheitlich; такие существительные как die Einheit (единство), das Einhorn (единорог), die Einzahl (ед. число); глаголы einigen (объединять), einwiegen (уравновешивать), einwilligen (соглашаться) и др. $[5,120]$.

Количественное имя числительное служит основой для образования всех остальных числительных. Прямо или косвенно на него опираются порядковые, кратные, дробные и другие имена числительные.

Имя числительное как в даргинском, так и в немецком языках характеризуется наличием в нем целого ряда специфических разрядов с лексико-грамматическими особенностями. Как известно, понятие числа является семантической основой имен числительных, как части речи. Числительные относятся к именным частям речи, т.к. имеют ряд общих свойств с именами существительными и прилагательными, как с точки зрения синтаксического употребления, так и состава грамматических категорий и словоизменения.

Количественные числительные даргинского языка, выполняя функцию зависимого компонента, в словосочетаниях не согласуются со стержневыми компонентами ни в классе, ни в числе: $x$ 1ябал урши букв. «три мальчик», шел рурси «пять девочка» и т.д. Стержневой компонент - имя существительное, определяемое зависимым числительным, всегда ставится в даргинском языке в единственном числе и по отношению к зависимому компоненту занимает в предложении постпозитивное положение. Сравните: чеч., инг, бацбб. пхи машина - «пять машин», чеч., инг. итт машина, бацб. um 1m1 машина «десять машин», во всех этих словосочетаниях имя существитель- 
ное «машина» используется в именительном падеже единственного числа $[9$, с. 12]. Дагестанские языки обнаруживают одну примечательную особенность реализации лексического способа выражения числа, осуществляемую через соответствующие мыслительные единицы. Эта особенность заключается в том, что дискретное (или прерывное) количество выражается сочетанием любого числительного с существительным, стоящим исключительно и непременно в единственном числе. Как пишет по этому поводу С.М. Хайдаков: «В синтагме ацІІва ниц, что буквально означает «десять бык», существенным образом меняется само понятие дискретного количества: оно мыслиться как такое количество, которое состоит лишь из отдельной, изолированной единицы - в данном случае этой единицей является название животного ниц «бык», а сочетание его с числительным ацІва «десять» дает понятие дискретного количества, которое соразмеряется с числом «десять», но явно противоречит числовой форме существительного ниц «бык», которая, как правило, стоит в единственном числе» $[11$, с. 7]. Такое положение вещей наблюдается не только в лакском языке, но и во всех дагестанских языках, например: аварский язык: анцІгоои букв. «десять бык», къого чу «двадцать лощадь», щуго яс «пять девочка»; даргинский язык: вецІал уни, гъалябу, шел рурси; чеченский язык: иттсиу, тІкъаговр, пхийуоI.

Числительные в даргинском языке характеризуются определением предмета с его количественной стороны, причем в отличие от некоторых прилагательных и местоимений, также выражающих количество, числительное выражает количество точно.

Имена числительные в немецком языке, как и имена прилагательные, выступают в качестве определения при имени существительном, например: derkleine Junge. Подобно именам существительным и прилагательным, многие имена числительные склоняются, изменяются по родам, например: der zweite Versuch, ein zweiter Versuch, nach dem zweiten Versuch. Реже имена числительные сходны с наречиями и переходят в них. Отметим, что не все исследователи считают числительное отдельной частью речи, так, например, В. Юнг не выделяет числительные в самостоятельную часть речи [14, с. 180]. 
В разносистемных даргинском и немецком языках обнаруживаются некоторые параллели в системе распределения видов числительных.

Числительные в даргинском языке делятся на количественные, порядковые, дробные, кратные, распределительные. В простых числительных даргинского языка от 2 до 100 различаются две составные части, корень и суффикс: $x 1$ яб+ал «три», верx $1+e л$ «семь», дарши ал «сто» и т.д.

Отметим, что в лакском и в некоторых других языках Дагестана числительные снабжены классными показателями, которые согласуются в зависимости от класса определяемого имени. Например, в лакском языке кlия 1 класс «два», кluва 3класс, кlpaa 2, 4 классы [7, c. 71]. В даргинском языке числительные по классам не изменяются.

Порядковые числительные в даргинском языке образуются прибавлением простого числительного или причастия к составному числительному ибил/эсил «сказанный»: веи Іъибил «десятый», гъаэсил «двадцатый», ияаэил «первый», вец1ну кlира ибил «двенадцатый» и т.д. Такое же положение и в других дагестанских языках (аварском, лакском, табасаранском, лезгинском) порядковые числительные образуются тем же способом.

Дробные числительные в дагестанских языках развиты слабо. В даргинском языке для выражения понятия «половина» существует слово байхъала (где б является классным показателем). Этимология данного слова восходит к слову бай «середина, центр», а байбя хъес означает «резать пополам». Для выражения понятия «четверть» используют слово авбаркьала (ав «четыре»+баркь «деление», -ала «словообразовательный суффикс»). Остальные дробные числительные в даргинском и в других дагестанских языках выражаются описательно: шел бут 1ала иза бутla «одна пятая» и т.д.

Кратные числительные образуются при помощи суффикса - на: $x 1$ яй + на «три раза», $а в+н a$ «четыре раза», вец $1+$ на «в десять раз» и т.д.

Распределительные числительные со значением «по одному», «по два» в даргинском языке образуются повторением основ: $\kappa l u$ к1ел «по два», х1яб-х1ябал «по три», шу-шел «по пять», вец 1-вецุ1ал «по десять» и т.д. 
Количественные числительные в даргинском языке не располагают какой-либо грамматической категорией, в том числе и категорией падежа. Склонению такие числительные подвергаются только при их субстантивации. С.Н. Абдуллаев пишет, что «Склонение числительных в даргинском языке имеет некоторые особенности: в числительных от 2 до 10 и в круглых десятках, 20 и 100 - все косвенные падежи образуются от корня числительного без суффикса -ал, причем эргатив принимает показатель кlел «два» - кlили, кlила, кlилис, кlиличил; в других числительных косвенные падежи образуются от полного чис-

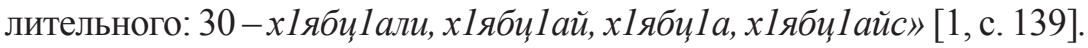

В других дагестанских языках картина склонения имени числительного примерно такая же. Например, в цахурском языке числительные при самостоятельном употреблении также склоняются. В парадигме склонения числительных с учетом особенностей оформления косвенной основы выделяются два типа склонения [3, с. 98].

Числительные в немецком языке делятся на два структурносемантических разряда: 1) определенно-количественные числительные и 2) неопределенно-количественные числительные. Определенно-количественные числительные в свою очередь подразделяются на: а) количественные; б) порядковые; в) дробные.

Основная масса количественных числительных является неизменяемыми словами. Кстати, неизменяемость определенных количественных числительных в немецком языке является одной из схожих черт грамматического строя немецкого языка с даргинским, так как в даргинском, как в других дагестанских языках, количественные числительные также не имеют развитую систему склонения. А такие слова как миллион, миллиард являются заимствованными через русский язык.

К количественным числительным примыкают по своим функциям и по значению счетные существительные. К ним относятся: a) Интернациональные слова: die Million, die Milliarde, die Billion. Соответственно они склоняются как имена существительные: eine (die) Million, einer (der) Million, (die) Millionen, например: eine Million Rubel. Отметим, что и в дагестанских языках миллион, миллиард также 
склоняются как существительное; б) Счетными существительными являются также das Hundert (des Hunderts, die Hunderte) и das Tausend (des Tausends, die Tausende). Производными от них являются неизменяемые количественные числительные hundert и tausend. Счетные числительные даргинского языка, образуются сочетанием числительных, занимающих соседние позиции в ряду натуральных чисел, ср. кІел-хІябал - «два-три». Эти формы даргиноведы относят к сложным словам [6, с. 119]. Порядок следования компонентов в подобных композитах подчиняется принципу «цифровой последовательности»: иุaчIwел - «один-два», хьжел-уреккал - «пятышесть» (т. е. последовательности «два-один» или же «шесть-пять» невозможны) [4].

Имена существительные das Hundert и das Tausend употребляются либо как единицы меры: ein Hundert Zigarren, ein halbes Hundert, либо в формах множественного числа для обозначения неопределенного большого количества, где допускается двоякое написание с заглавной и строчной буквы.

Порядковые числительные обозначают порядковое место предмета при счете. Выступая в функции определения в составе атрибутивного словосочетания, порядковые числительные склоняются как имена прилагательные. Подобно прилагательным также изменяются по числам и родам: der erste Mai; die ersten Schritte; ihr erstes Schuljahr; der vierte Fünfjahrplan.

Дробные числительные обозначают дробные величины. Являясь по происхождению существительными, дробные числительные сохраняют некоторые свойства имен существительных, например, написание с заглавной буквы (ein Drittel, ein Achtel, ein Hundertstel). Поэтому в научной литературе по германистике мнения по квалификации дробных числительных расходятся. Дробные числительные не согласуются с определяемым именем существительным; они сохраняют в соответствии со своим происхождением тип флексии имен существительных: ein Drittel, eines Drittels, zwei Drittel.

Счетным прилагательным, имеющим значение дробного числительного, но сохраняющим флексию имени прилагательного, является halb: ein halbes Kilo, ein halber Tag - einen halben Tag. 
Неопределенно-количественные числительные в немецком языке, как указывает их название, заключают в себе указание на большое или малое количество предметов, не называя, однако, точного их числа [15]. К данному типу числительных относится весьма немногочисленная группа слов, как простых, так и производных, например: alle, gesamte, ganze, beide, einige и другие.

Вышеперечисленные слова представляют собой в грамматическом и семантическом отношении особую группу. Среди германистов нет единого мнения по вопросу квалификации данных лексем. Некоторые лингвисты (В. Юнг и его последователи) указывают на возможность рассмотреть эти слова среди числительных [13, с. 353].

Е.В. Гулыга и Е.И. Шендельс полагают возможным квалифицировать данные лексемы как количественные местоимения, учитывая при этом их особый характер. Они разделяют вместе со всеми местоимениями их свойства; указательность, относительность своего содержания и др. Они отличаются от таких местоимений, как dieser - jener тем, что выражают количественные отношения. Они дают большей частью общую и неточную количественную характеристику тому предметному понятию, с которым они соотносятся. Они выражают неопределенную множественность - семы «множественность» и «неопределенное количество» (кроме beide), но, помимо этого, они способны передать целую гамму числовых значений, начиная от «тотального множества» (alle) и кончая нулем (keine). Обычно они сопровождают существительное во множественном числе (или соотносятся с ним в макроконтексте), присоединяя свои семы к семе «множественность» и конкретизируя тем самым понятие множества. Alle и sämtliche - синонимы, которых объединяет, кроме вышеуказанных двух сем, сема «тотальность». Они указывают на то, что ни один член множества не отсутствует. Они сочетаются со всеми названиями исчисляемых понятий во множественном числе: alle (sämtliche) Fenster, Völker, Freuden. Alle отличается от sämtliche более высокой частотой употребления, многозначностью (alle может иметь значение «кончилось», «все», например: Zucker istalle = Zucker ist ausgegangen, cp. pус. «сахар весь вышел». 
Alle может употребляться: 1) не как сопроводитель существительного, а самостоятельно: Alle (Menschen) stimmenbei. В среднем роде: Allesspaziert, alle slacht - в значении «все люди вокруг», (прием встречается в художественной литературе); 2) в сочетании с личными местоимениями множественного числа: wir alle; sie alle; 3) в сочетании с числительным и существительным во множественном числе: Alle zehn Schritte, allezwei Monate.Сема «тотальность» относится ко всему сочетанию zehn Schritte, zweiJahre, представляя его как единый отрезок; кроме того, в результате идиоматичности словосочетания появляется новая сема «регулярность» (повторность с равными интервалами); 4) в сочетании с существительными в единственном числе, не имеющими формы множественного числа: alle Mühe, aller Einsatz [2, с. 27].

Alle не сочетается с именами собирательными и вещественными в единственном числе. При необходимости передать сему «тотальность» в отношении этих понятий привлекается слово ganz. Cp.: die ganze Studentenschaft, но alle Studenten; das ganze Geld, но alle Gelder, all mein Geld. Слово ganz обладает только семой «тотальность», но не семой «множественность», что обуславливает смысловое различие в следующих двух словосочетаниях: alle Welt (jedermann) - dieganze Welt (universum). По этой же причине alle не может заменить ganz в сочетаниях: der ganze Staat, der ganze Mensch, das ganze Buch.

Числительные в немецком языке функционируют также как выразители определенного количества. Числительные дают точную количественную информацию: 2, 10, 25 Jahre, или информацию о порядковом номере: das zweite Jahr. Они выражают определенную множественность. Они обладают семами «множественность» и «определенность количества» (кроме чисел eins и null) и противостоят, таким образом, количественным местоимениям. Подобно последним они сопровождают существительное, конкретизируя количественные отношения. Можно установить смысловую оппозицию:

$$
\text { сема } \leftrightarrow \text { сема }
$$

«неопределенное множество» «неопределенное множество» количественные местоимения числительные 
Между этими двумя противоположными по значению группами может произойти сближение. Так, местоимение beide равно по значению числительномy zwei, а местоимение keine - числительному null. Иногда числительные zwei, drei, vier, fünf синонимичны местоимению einige: Aufzwei Worte; Ich brauche bloss zwei, drei Nagel und einen Hammer.

Существительные-числительные das Dutzend, das Hundert, das Tausend, die Million, несмотря на свое конкретное числовое значение, часто употребляются синонимично местоимениям viele, mehrere: Dutzend Fragen; Hunderte, Tausende von Menschen; Tausende und aber Tausende; Millionen und abermals Millionen.

С последующим существительным эти слова могут соединяться одним из трех способов: ein Dutzend der Löffel - малоупотребительно; ein Dutzend von Löffeln - употребительно; ein Dutzend Löffel наиболее употребительно.

Хотя в этих случаях числительные передают не совсем точную количественную информацию, она точнее, чем информация местоимений, так как позволяет судить приблизительно о количестве элементов множества.

Небольшая группа существительных в дагестанских языках также располагает двумя формами множественного числа, выражающими ограниченное и неограниченное множество, где анализируется ряд лексем с двумя формами множественного числа, например, в аварском языке: чед «хлеб»-чед-ал (мн.ч. огран. кол.); чад-ал (мн. ч. неогран. кол.) [10, с. 114-119].

Как показывают примеры, форма ограниченного множественного числа отличается от формы неограниченного множественного числа рядом признаков: характером оформления основы, позицией ударения и т.д.

Полагаем, что сопоставительное изучение разноструктурных языков: английского, немецкого, французского и дагестанских позволит существенно расширить лингвистико-теоретический кругозор языковедов. Так что, задача системного исследования сопоставительной грамматики данных языков является на сегодняшний день весьма актуальной. 


\section{Список литературы}

1. Абдуллаев С.Н. Грамматика даргинского языка. Махачкала: Институт истории, языка и литературы Дагестанского филиала АН СССР, 1954. $216 \mathrm{c}$.

2. Гулыга Е.В., Шендельс Е.И. Грамматико-лексические поля в современном немецком языке. М.: Просвещение, 1969. 184 с.

3. Ибрагимов Г.Х. Цахурский язык. М.: Издательство «Наука», 1990. $120 \mathrm{c}$.

4. Кадибагомаева 3.А. Словообразование в сирхинском диалекте даргинского языка (на материале нахкинского, нацинского и цугнинского говоров). Дисс .... к.ф.н. Махачкала, 2009. 179 с.

5. Колотилова Н.С. Числительные 1, 2, 3 в немецком языке: новые образования и древние реликты // Вестник Рязанского государственного университета, 2015. № 1 (46). С. 116-125. (дата обращения 8.10.2018).

6. Курбанова Э.О., Солодовникова О.К. Сложные числительные в даргинском и английском языках // Проблемы современной науки и образования, 2015. №10 (40). С. 117-119.

7. Мусаева Х.М. Неопределенно-количественные числительные в русском и лакском языках // Гуманитарные исследования №3 (35) 2010. C. $70-73$.

8. Насырова А.Б., Коурова О.В. Символика чисел в немецком языке: результаты опроса информантов // Проблемы романо-германской филологии, педагогики и методики преподавания иностранных языков № 7. 2009. С. 48-55. 9. Сулейбанова М.У., Шовхалова Д.С. Числительные в нахских языках // Перспективы развития современных гуманитарных наук, 2017. С. 10-13.

9. Сулейманов Я.Г. О формах ограниченного и неограниченного множественного числа имен существительных в аварском языке // Категория числа в дагестанских языках. Махачкала, 1985. С. 114-119.

10. Хайдаков С.М. Принципы именной классификации в дагестанских языках. М.: Наука, 1980. 251 с.

11. Челнокова А.А. Имена числительные как мотивационная база вторичной номинации в немецком языке: автореф. дис. ... к.ф.н.. Самаpa, 2009. 24 c. 
12. Glinz H. Die innere Form des Deutschen. Eine neue deutsche Grammatik. 4. Aufl. Bern - München, 1965.505 c.

13. Jung W. Grammatik der Deutschen Sprache. Leipzig, 1966. 204 c.

14. Trabandt C., Sanfelici E., Thiel A., Schulz P. On the acquisition of ordinal numbers in German. GALA Proceedings 2013. C. 521-532.

\section{References}

1. Abdullaev S.N. Grammatika darginskogo yazika [The grammar of the Dargwa language]. Makhachkala: Institut istorii, jazyka i literatury Dagestanskogo filiala AN SSSR, 1954. 216 p.

2. Guliga E.V., Shendels E.I. Grammatiko-leksicheskiye polya v sovremennom nemetskom yazike [Grammatical-lexical fields in the modern German language]. Moscow: Prosveshhenie, 1969. 184 p.

3. Ibragimov G.H. Tsakhurskiy yazik [The Tsakhur language]. M.: Nauka, 1990. 120 p.

4. Kadibagomayeva Z.A. Slovoobrazovanye v sirhinskom dialekte darginscogo yazika (na materiale nahkinscogo, natcinskogo ye tcuginscogo govorov) [Word formation in the Sirkhin dialect of the Dargha language (on the material of the Nakhkin, Natsin and Zugna dialects)]. Diss. ... k.f.n. Makhachkala, 2009. 179 p.

5. Kolotilova N.S. Chislitelnye 1,2,3 v nemetckom yazike: novye obrazovaniya ye drevnye relikty [The numerals 1,2, 3 in the German language: new formations and ancient relics]. Vestnik razanskogo gosudarctvennogo universiteta, 2015. № 1 (46), pp. 116-125.

6. Kurbanova E.O., Solodovnikova O.K. Slozhniye chislitelniye v darginskom ye angliyskom yazikah [Complex numerals in the Dargin and English languages]. Problemy sovremennoy nauki ye obrazovaniya, 2015. №10 (40), pp. 117-119.

7. Musayeva H.M. Neopredelenno-kolichestvenniye chislitelniye v russkom ye lakscom yazikah [Indefinite-quantitative numerals in the Russian and Lakh languages]. Gumanitarniye issledovaniya №3 (35), 2010, pp. 70-73.

8. Nasirova A.B., Kourova O.V. Symvolika chisel v nemetckom yazike: rezultati oprosa informantov [The symbolism of numbers in the Ger- 
man language: the results of a survey]. Problemy romano-germanskoy filologiye, pedagogiky i metodiky prepodavaniya inostrannih yazikov, № 7, 2009, pp. 48-55.

9. Suleymanov Ya.G. O formah ogranichennogo ye neogranichennogo mnozhestvennogo chisla yemen sushestvitelnih v avarskom yazike [On forms of the definite and indefinite plural of nouns in the Avar language]. Kategorija chisla $v$ dagestanskih jazykah [Category of the number in Dagestan languages]. Makhachkala, 1985, pp. 114-119.

10. Haidukov. S.M. Printcipy yemennoy klassifikatciye $v$ dagestankih yazikah [Principles of nominal classification in the Dagestan languages]. M: Nauka, 1980. 251 p.

11. Chelnokova A.A. Imena chislitelniye kak motivatcionnaya baza vtorichnoy nominatciye $v$ nemetckom yazike [Numerals as a motivational base for secondary nomination in the German language]. Avtoref. diss. k.f.n. Samara, 2009. 24 p.

12. Glinz H. Die innere Form des Deutschen. Eine neue deutsche Grammatik. 4. Aufl. Bern - München, 1965. 505 p.

13. Jung W. Grammatik der Deutschen Sprache. Leipzig, 1966. 204 p.

14. Trabandt C., Sanfelici E., Thiel A., Schulz P. On the acquisition of ordinal numbers in German. GALA Proceedings 2013, pp. 521-532.

\section{ДАННЫЕ ОБ АВТОРАХ}

Мишаева Марианна Владимировна, канд. филол. наук, доцент кафедры иностранных языков для естественнонаучных факультетов Дагестанский государственньй университет ул. Коркмасова 8, г. Махачкала, Дагестан, Российская Федерация mishmar78@mail.ru

Мутаева Саида Ибрагимовна, канд. филол. наук, доцент кафедры иностранных языков для естественнонаучных факультетов Дагестанский государственный университет ул. Коркмасова 8, г. Махачкала, Дагестан, Российская Федеращчия 
suzon09@list.ru

ORCID: 0000-0002-9259-3936

\section{DATA ABOUT THE AUTHORS}

Mishaeva Marianna Vladimirovna, Candidate of Philology, Associate Professor of the Department of Foreign Languages for Faculties of Natural Sciences

Dagestan State University

8, Korkmasova st., Makhachkala, Dagestan, Russian Federation mishmar78@mail.ru

Mutaeva Saida Ibragimovna, Candidate of Philology, Associate Professor of the Department of Foreign Languages for Faculties of Natural Sciences

Dagestan State University

8, Korkmasova st., Makhachkala, Dagestan, Russian Federation suzon09@list.ru

ORCID:0000-0002-9259-3936 